NASZA DERMATOLOGIA Online OUR DERMATOLOGY Online

Source of Support: Nil

Competing Interests: None

\section{CHRONIC ULCERATING GENITAL HERPES SIMPLEX VIRUS INFECTION: A DIAGNOSIS MISLEAD BY HIV INFECTION}

\author{
Sudip Parajuli, Yogesh Acharya, Sandhya Bagariya Rathi, \\ Upama Paudel
}

Department of Dermatology, Maharajgunj Medical Campus, Tribhuvan University

Teaching hospital, Kathmandu, Nepal

Corresponding author: Dr Sudip Parajuli

sudipparajuli@gmail.com

\begin{abstract}
We report a case of chronic herpes simplex in a 27 year old lady presenting with a history of persistent verrucous ulcer in the natal cleft of nine months duration. The patient was diagnosed and treated initially as a case of Tuberculosis Verrucosa Cutis (TVC) based on the chronicity of the ulcer, negative HIV serological tests and histopathological findings. The diagnosis had to be revised as the lesion was increasing in size and the patient was not responding to treatment even after completing antituberculous treatment for six months. Repeat histopathological examination and immunohistochemistry showed DNA of herpes simplex. Based on this finding a repeat HIV serology was sent which was positive. The ulcer healed after a course of acyclovir. The case is being reported to highlight the importance of considering chronic herpes simplex infection in a case of chronic genital ulcer. In addition this case reminds us the nature of HIV infection to mislead the diagnosis by altering the natural course of the disease process.
\end{abstract}

Key words: Herpes; HIV; Verruocous ulcer; Acyclovir; Tuberculosis Verrucosa Cutis; Genitalia

Cite this article:

Parajuli S, Acharya Y, Rathi SB, Paudel U. Chronic ulcerating genital herpes simplex virus infection: A diagnosis mislead by HIV infection. Our Dermatol Online. 2014; 5(3): 285-286

\section{Introduction}

Herpes simplex virus type 2 (HSV-2) infections is the most common cause of genital ulcerative disease in the developed world. Its etiological agent is herpes simplex virus type 1 (HSV-1) or 2 (HSV-2). The principal route of infection with HSV is asymptomatic viral shedding. The infection is life-long; despite treatment [1]. The clinical polymorphism of Chronic herpes simplex virus (CHSV) and chronic varicella zoster virus (CVZV) makes their recognition difficult [2].

We report a case of chronic ulcerating genital herpes simplex virus infection in a HIV infected patient because of the tendency on part of physician to overlook the diagnosis when HIV infection is not suspected.

\section{Case Report}

A 27 year, widow from Palpa district of Nepal presented with a single, asymptomatic, $3 \times 2 \mathrm{~cm}$ mobile and non indurated verrucous plaque over natal cleft since nine months which was slowly progressing. It was associated with low grade fever that subsided spontaneously. She was diagnosed as Tuberculosis Verrucosa Cutis (TVC) on the basis of clinical, laboratory (Total WBC count: 6310; N48, L45, ESR: 60mm Wintrobes, Mantoux test: induration diameter $=0 \mathrm{~mm}$ ) and histopathological findings (neutrophilic and lymphoplasmacytic infiltrate, necrosis with aggregates of epitheloid cells, Periodic acid Schiff and Ziehl Nelson Stain were negative). She was started with a course of Anti-Tubercular Therapy (ATT) which was followed by decreasing size of the lesion during the initial one month period. Gradually, after two months, the lesion started ulcerating and she also developed new well defined $1 \times 1 \mathrm{~cm}$ discrete, punched out, non tender, kissing ulcers over labia minora (Fig. 1). Her serology for HIV was negative. VDRL and pathergy tests were also negative. A repeat biopsy was done and the histopathological findings showed chronic ulcer with vague granulomatous reaction in the dermis; suggestive of healing tuberculous lesion. ATT was continued for 6 months but no improvement was noted and she was also started with oral doxycycline with slight improvement in the first two weeks.

The patient lost follow up for 4 months and had discontinued the medication when she presented to us. The lesions had now coalesced to form two large painful ulcers with sero-purulent discharge involving the peri-anal area and the labia minora. Other mucosal surfaces, hair and nails were spared. There was no lymphadenopathy, no history of night sweats, weight loss, and decreased appetite, joint pain, bleeding manifestations or ophthalmic problems. 
There was no history of blood transfusion and extra-marital sexual relationship. Her husband, who worked abroad, expired eight years back because of pulmonary tuberculosis.

The patient was not responding to any of the treatments provided which prompted us to revise the diagnosis. On further histopathological work up, Immunohistochemistry for Herpes Simplex virus type $1 / 2$ was positive with reactivity in the nuclei

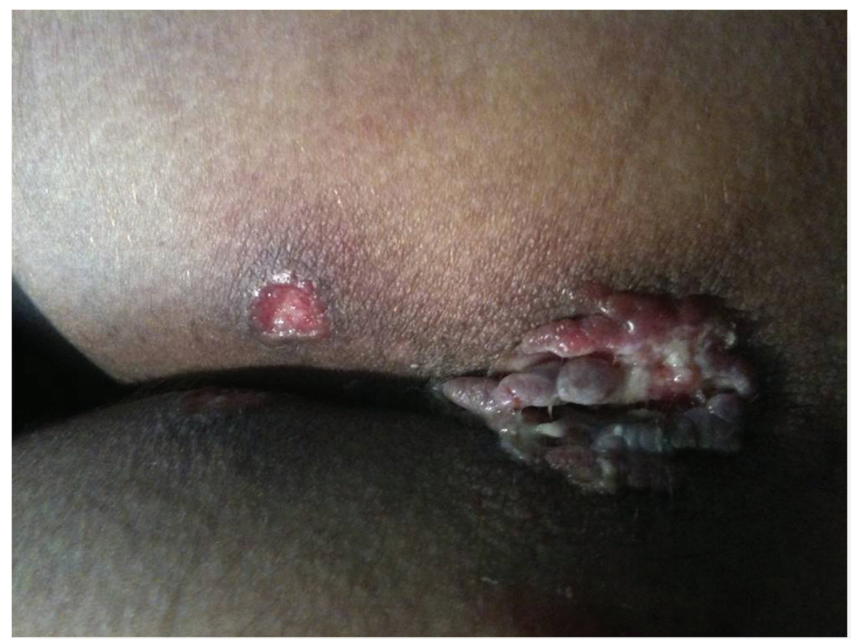

Figure 1. Verrucous ulcer in anogenital area at presentation.

\section{Discussion}

Genital herpes is the most frequent cause of genital ulcer diseases. Other agents responsible for genital ulceration are Haemophilus ducreyi, Treponema pallidum, Kleibsiella granulomatis, Chlamydia trachomatis (LGV strain) [4]. Herpes is the fourth commonest sexually transmitted disease; the first 3 being chancroid, gonorrhoea, and genital warts; genital herpes accounts for $22.4 \%$ of the new patients [5]. In the United States of America it is commoner than gonorrhoea and has increased 9 folds in the last 2 decades [6,7]. Also in a study done by Shobhana et al, out of 410 HIV seropositive patients $40 \%$ had mucocutaneous involvement and genital herpes was the most common genital ulcer disease [8].

Herpes simplex is known to occur as a manifestation of AIDS, where it is more severe and atypical and perianal lesions are characteristic [9]. In our patient the presentation was a persistent mucocutaneous wart-like and ulcerative infection, which is one of the commonest atypical presentation of chronic herpes simplex virus infetion associated with HIV. It may occasionally present with other types of immunosuppression as well [3]. Low CD4+ counts also act as a marker of HIV disease progression [10].

\section{Conclusion}

A high index of suspicion is necessary to pick up a case of HIV positivity from an outpatient department. HIV can lead to bizarre presentation of common conditions like herpes, so awareness of the disease and its various manifestations becomes immensely important for proper diagnosis and treatment of our patients. of enlarged and multinucleated keratinocytes. Also a repeat serology for HIV was sent which to our surprise was positive with CD4 count of 39 cells $/ \mathrm{mm}^{3}$. She was then started on Acyclovir 200mg five times a day with improvement after first week of therapy (Fig. 2). She was also started on anti-retroviral drugs.

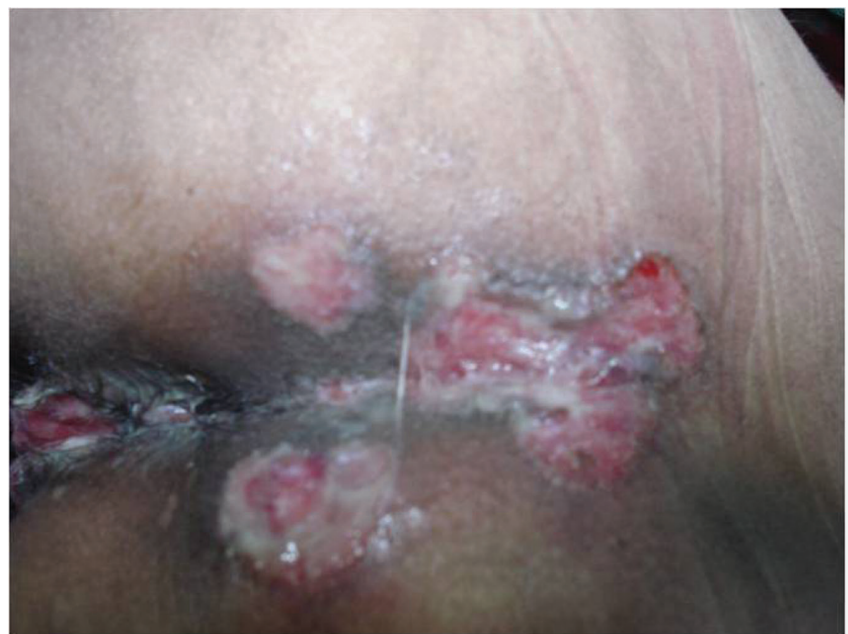

Figure 2. Healing ulcer 7 days post treatment with acyclovir.

\section{REFERENCES}

1. Kumar B, Sehgal S. Genital herpes - A maker of HIV infection. Indian J Dermatol Venereol Leprol. 1990;56:387-8.

2. Shao Y, Zhang W, Dong X, Liu W, Zhang Ch, Zhang J, et al. Keratinocytes play a role in the immunity to Herpes simplex virus type 2 infection. Acta Virol. 2010;54:261-7.

3. Wauters O, Lebas E, Nikkels AF. Chronic mucocutaneous herpes simplex virus and varicella zoster virus infections. J Am Acad Dermatol. 2012;66:e217-27.

4. D'Souza K, Tendolkar UM, Deodhar LP. Multiple aetiologic agents causing penile ulcers in an HIV-antibody positive patient. Indian J Dermatol Venereol Leprol. 1993;59:35-6.

5. Verma KK, Seth P, Bhutani LK. Serotyping in herpes simplex virus infection. Indian J Dermatol Venereol Leprol. 1994;60:136-9.

6. Gardner H L, Kaufman R H. Herpes genitalis Clinical features. Clin Obst Gyne. 1972;15:896-911.

7. Amletey M S. Genital herpes virus infection. Clin Obst Gyne. 1975;18:89.

8. Shobhana A, Guha SK, Neogi DK. Mucocutaneous manifestations of HIV infection. Indian J Dermatol Venereol Leprol [serial online]. 2004;70:82-6.

9. Kumar B, Sehgal S. Genital herpes - A maker of HIV infection. Indian J Dermatol Venereol Leprol 1990;56:387-8.

10. Sen S, Halder S, Mandal S, Pal PP, Halder A, Bhaumik P. Clinicoepidemiological profile of cutaneous manifestations among human immunodeficiency virus positive patients in the sub-Himalayan region. Indian J Dermatol Venereol Leprol. 2009;75:403-5.

Copyright by Sudip Parajuli, et al. This is an open access article distributed under the terms of the Creative Commons Attribution License, which permits unrestricted use, distribution, and reproduction in any medium, provided the original author and source are credited. 